\title{
Tackling the Kanji hurdle: Investigation of Kanji learning in Non-Kanji background learners
}

Paxton, Simon

Macquarie University, Australia (simon.paxton@students.mq.edu.au)

Svetenant, Chavalin

Macquarie University, Australia (chavalin.svetanant@mq.edu.au)

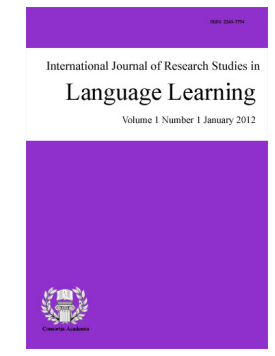

ISSN: $2243-7754$ Online ISSN: 2243-7762

OPEN ACCESS

\section{Abstract}

Although Kanji is widely recognized as the most difficult hurdle to overcome in learning Japanese, little research has been undertaken on the selection and order in which Kanji are taught to Japanese students from non-Kanji backgrounds. In this study, the criteria for different orders of kanji are analyzed in respect with their pedagogical merits in teaching Kanji to students of Japanese from non-Kanji backgrounds. The principal objective of this study is to redress the lack of research in this area and the lack of uniformity in Kanji education. Overall, the orders Kanji are taught seems to be mostly arbitrary and is not considered to be of any great importance in aiding students attain Kanji proficiency. This paper examines the difficulty of Kanji for non-Kanji background learners and finds that Kanji order is indeed a vital consideration in developing more efficient Kanji teaching and learning strategies for students from non-Kanji backgrounds.

Keywords: non-Kanji background learners; Kanji acquisition; second language acquisition; learning strategies; memory strategies 


\section{Tackling the Kanji hurdle: Investigation of Kanji learning in Non-Kanji background}

\section{learners}

\section{1. introduction}

Japanese language has long been regarded as one of the most difficult languages in the world (Miller, 1971). It is perhaps not surprising; therefore, that sixteenth century Portuguese missionaries regarded Japanese as a language invented by the devil. On average, the Japanese language takes three times longer to learn than a European language, and even native Japanese speakers argue that their language is difficult, not only for foreigners but for Japanese native speakers as well (Kindaichi, 1978). Japanese is included in the "category four" languages (Chinese, Japanese, Korean and Arabic - all non-western orthographic languages). "Category four" is a term used by the Foreign Service Institute and the Defense Language Institute to classify languages according to the time taken to attain varying levels of proficiency (Grainger, 2005).

The difficulty of learning Japanese is believed to be largely due to the complexity of its written language, especially that part of the writing system known as the "kanji" (Bourke, 1996; Gamage, 2003). The difficulty of the Japanese written script contributes to high rates of attrition amongst students from non-Kanji backgrounds (Grainger, 2005). The Japanese Ministry of Education (Monbukagakusho) has arranged the Jouyou kanji into a specific order for which they are to be taught in the Japanese educational system. The kanji are arranged in a frequency-based order, that is, the most commonly used kanji are taught first. By the end of their sixth year of primary school, students have learned the 1006 kyouiku kanji recognized as the most commonly used of all 2136 kanji in use. It is estimated that these 1006 kanji alone make up 95\% of actual kanji usage in print (Kess, 1999). Table 1 below outlines the number of kanji learned in elementary school by year in Japan.

\section{Table 1}

Number of Kanji Learned Per Grade in the Japanese Educational System (Kyouiku Kanji)

\begin{tabular}{ll}
\hline Grade & Number of kanji \\
\hline 1 & 80 \\
2 & 160 \\
3 & 200 \\
4 & 200 \\
5 & 185 \\
6 & 181 \\
Total & 1006 \\
\hline
\end{tabular}

Japan has one of the highest literacy rates in the world; however, Japanese native speakers spend twelve years of their education studying the Jouyou Kanji, and even Japanese people sometimes struggle to remember the correct kanji. According to Mainichi Shimbun newspaper, (March, 2008), of the third year high school students taking level 2 of the Japanese Kanji Aptitude Test - the high school graduate level which includes the reading and writing of the Jouyou Kanji-there has been a pass rate of below twenty percent for ten consecutive years. Considering that the sheer number of kanji presents difficulties for native Japanese speakers, it is no surprise that mastering kanji is a complex and daunting task for learners from alphabet-based languages.

The length of time taken for native Japanese speakers to learn kanji raises questions as to how kanji should best be taught to Japanese as Foreign Language (JFL) students. Learning kanji the Japanese way takes a long time and requires considerable motivation on the part of JFL students who are limited in their exposure to kanji in everyday life. Moreover, the order in which the kanji are taught to native Japanese seems to have no logical progression other than the fact that the more frequently used kanji are taught first. For JFL students who have limited exposure to real Japanese, frequency is perhaps not the best criteria for ordering kanji. 
Tackling the Kanji hurdle: Investigation of Kanji learning in Non-Kanji background learners

This paper aims to explore the problems and relevant theories regarding kanji learning in non-kanji background learners. It also aims to investigate various types of kanji ordering strategies which can potentially be implemented as an efficient learning strategy for JFL learners from non-kanji backgrounds. In order to achieve this, this paper provides an overview of kanji education and its difficulties, theories of second language acquisition and cognitive science in relation to kanji learning, and kanji learning strategies. Finally, several criteria for ordering kanji are considered. The aim of this paper is not to purport any one method of ordering or teaching kanji as the best method but rather to explore and raise awareness of how the order in which kanji are introduced is an important factor in kanji education for students from non-kanji backgrounds.

\section{Overview of Kanji Education}

With respect to kanji education at the university level in Australia, there are no clear guidelines in terms of how much university graduates are expected to know by the time they graduate. Is it too much to ask that students become proficient in the everyday kanji by the time they graduate? If not, how many kanji should students is expected to know by the time they graduate? There is no uniformity with regards to answers to these questions. The order in which kanji are taught also seems to be at the discretion of the teacher with no specific guidelines and little time devoted to devising a specific, and logically-derived, order for teaching kanji.

According to a survey by the Japan foundation (2011, p. 1), the number of students studying Japanese outside Japan had reached 3,651,232 in 2009, a 22.5\% increase since the previous survey in 2006 (See: p.2 of the same report). Although slight declines in the number of students studying Japanese in some countries is evident, the popularity of Japanese as a foreign language is indisputable.

Despite the popularity of Japanese as a foreign language, Japanese language classes experience high attrition rates at secondary and tertiary levels (Grainger, 2005). For non-kanji background learners, learners of Japanese whose native language (L1) does not incorporate the use of "Chinese characters" (kanji), acquiring proficiency in the reading and writing of kanji is perhaps the greatest obstacle to overcome in mastering the language (Tollini, 1994). In particular, it is recognized that character based languages such as Japanese are difficult for learners whose L1 is alphabet-based (Bourke, 1992; Douglas, 1992).

Despite the difficulty of kanji acquisition, kanji are an indispensable part of learning Japanese as it is essential for fluent reading and an essential element of the Japanese writing system (Mori, 2003). Grainger (2005) notes that advancement to higher levels of proficiency in orthographic languages for native learners of alphabet based languages like English may be more difficult than those languages based on alphabets, purely because of the difficulty in reading texts. Grainger (2005, p. 330) further notes that the inability to access written texts in a variety of forms (e.g. novel, newspaper, reference book) is an obvious 'delimiter to proficiency advancement'. Grainger's point is a pertinent one which highlights the need for advancing teaching methodologies and learner strategies to help learners from non-kanji backgrounds attain command of kanji. Unfortunately, kanji teaching methods and kanji learning strategies have done little to help students overcome this obstacle. In the Japan foundation report (2011, p. 12), for teacher-related problems, 'inadequate teaching methods' was the highest ranked problem. The report does not specify in which particular areas teachers find teaching methods inadequate, and therefore, we can only speculate as to what portion of that would relate to kanji teaching methods. For the most part, the kanji teaching methodology for learners of Japanese is the same as for native speakers of Japanese (Tollini, 1994). This approach however is troublesome for the student of Japanese as the orders the kanji are introduced seems to be random and lacking any sort of logical progression in which one kanji builds upon the next.

Furthermore, the difficulty of this approach is compounded by the fact that unlike native speakers of Japanese, who already have command of the spoken language when they commence kanji study, non-native learners of Japanese learn the written and spoken elements of the language simultaneously. Japanese native speakers spend several years studying kanji in the education system in Japan. Most foreign learners of Japanese 
do not have the same time to spend on learning kanji. Therefore, a more efficient method for teaching and studying kanji is needed.

\section{Literature Review}

Despite the fact that the selection and order that kanji are introduced to students from non-kanji backgrounds is of vital importance and central to the teaching methodology of kanji, much of the literature related to kanji education has focused on learning strategies for kanji, and there is a paucity of research in the area of instructional strategies for kanji with very little research or empirical studies conducted on the effect of different orders of kanji on retention. This is puzzling as learner strategies are often better implemented when kanji are grouped or organized into a specific order. In fact, in research on human memory, the role of organization on human memory is well established (Baddeley, 1999).

In a review of the literature in the area of second language acquisition and its application to kanji acquisition, the authors discovered that learning strategies have been the focus of much of the literature. Oxford (1990, p. 1), defines a learning strategy as 'steps taken by students to enhance their own learning.' Oxford (1990) breaks learning strategies into direct and indirect strategies which are further broken down into six smaller categories; memory strategies, social strategies, affective strategies, metacognitive strategies, compensation strategies, and cognitive strategies. For the purpose of this study, we are concerned with memory strategies and their application to kanji learning.

Oxford (1990, p. 14) classes memory strategies as direct strategies, and likens direct strategies to 'a performer in a stage play, working with the language itself'. In the case of kanji learning, however, in a classroom setting, it is the teacher who determines the order that kanji will be taught and therefore, these strategies as they pertain to kanji learning are just as much teaching strategies as they are learning strategies.

The teaching of kanji was a long neglected area in Japanese language teaching (Noguchi, 1995). However, there is growing interest in kanji education, and advances in cognitive psychology and second language research offer hope for advancement in kanji teaching methodology. The research questions posed for this study touch upon three primary areas of scholarship: literature on second language acquisition, cognitive theory, and kanji learning strategies.

\subsection{Second Language Acquisition}

In the field of second language acquisition, studies that examine the role of one's L1 on L2 acquisition have dominated the field. This literature is pertinent to this study because the focus group for this study is JFL students from non-kanji backgrounds. Therefore, the field of second language acquisition can offer insights into how one's L1 could affect kanji acquisition.

According to Nesbitt (2009), the English letters a-z triggers a sound association. When combined with other letters to make a word, a semantic value is activated; therefore, a degree of separation can be maintained between the simple phonetic-based alphabet and its lexical content. This is very different from kanji. According to psycholinguistics, there are three aspects of informational processes involved in processing kanji: orthography (grapheme), phonology, and semantics (Shimizu, 2002). According to Shimizu and Green (2002), the use of morphemes rather than phonemes represents a significant departure from the language decoding experience of most Westerners. This is certainly the case with kanji, by contrast however, hiragana and katakana are usually easily remembered by JFL students from alphabet based L1s probably because they are phonemic in nature, less visually complex, and the number of characters is much more manageable.

Ke (1998) in tests done to find the effect of language background on learning Chinese characters, found that there are no statistically significant differences between means of character recognition and production for heritage and non-heritage learners. In other words, the result suggests that for the analyzed sample, language 
Tackling the Kanji hurdle: Investigation of Kanji learning in Non-Kanji background learners

background-in this case, being a heritage learner or non-heritage one is not a variable influencing students' performance on Chinese character recognition and production. Ke (1998) admits however that the results of his tests could have been a result of "uneven work habits" between the two subgroups. That is, it is quite possible that the non-heritage group had more adequate study habits. Other factors such as motivation could well have influenced this outcome as well.

By contrast, Iwashita (2009) found that L1 and study background may influence the development of writing skills in Japanese as a second language. Iwashita, (2009) found that character based background language learners performed better on various aspects of kanji use due to the L1 influence.

In order to teach kanji more effectively to non-kanji background JFL learners, understanding how non-kanji background JFL learners perceive and process kanji is helpful. According to Fukuda et al, (1995, cited in Usuki, 2000 , p. 4), learners from non-kanji areas see kanji from a bottom-up perspective which moves from feeling perception - recognition -association of the meanings. Toyoda (1995, cited in Usuki, 2000, p. 5) reported from her survey results that learners from non-kanji areas tended to have difficulties in retaining what they have memorized rather than in memorizing the kanji itself. One might surmise from this that students could retain information in their Short Term Memory (STM) but had difficulty encoding information to their Long Term Memory (LTM) or to a sufficient depth of processing (See:3.2.2). This is a very common scenario in which students use rote learning to memorize kanji and can often produce good results in tests but fail to retain the information after testing.

\subsection{Cognitive Theory}

Cognitive psychology attempts to understand the nature of human intelligence and how people think (Anderson, 1980). Cognitive theories provide insight into how we process, store, and retrieve information. As learning a second language involves storage and retrieval of information, cognitive theories provide a relevant theoretical framework for understanding kanji acquisition. We will therefore examine some relevant areas of cognitive theory and their relevance to kanji acquisition.

Craik and Lockhart (1972) postulated a model for memory that characterized memory in terms of dual storage; short term memory (STM) and long term memory (LTM). STM is also sometimes referred to as primary memory, immediate memory, and working memory (Klatzky 1980, p. 11). In contrast to STM, Klatzky (1980) states that information in LTM seems to be arranged in a way that retrieval is accomplished with relative ease. In the case of kanji acquisition then, and if we are to accept the dual storage model of memory, the goal of kanji learning is to retain kanji in our LTM so that kanji can be easily retrieved.

Kanji learning strategies and teaching methodology must then be considered in relation to the task of storing kanji in the LTM. Unfortunately, there seems to be little agreement on how something initially stored in STM can subsequently become stored in LTM. Rote learning has been considered as one such method for retaining information in the LTM, however, some theorists argue that rehearsal only serves to maintain items in the STM and more active processing such as elaboration (see:3.2.6) are required for that information to be represented in the LTM (see: Klatzky, 1980, p. 12).

The depth of processing theory, in contrast to the dual storage theory, suggests that there is not two separate memory storages but rather different levels of processing in which deeper processing results in more elaborate, longer lasting, and stronger memory traces. When the learner analyzes for meaning, he may think of other related associations, images, and past experiences related to the stimulus. Factors which influence the depth of perceptual processing include the amount of attention devoted to the stimulus, its compatibility with existing memory structures in the learner's brain, and the amount of processing time available.

Moving things from STM to LTM is called encoding, or if we adopt the level of processing theory, encoding is achieving sufficient depth of processing. What methods help in the process of encoding? As stated earlier, 
repetition isn't regarded as an effective method of encoding information but rather more of a means of retaining information in the STM. Organization, meaningfulness, and imagery all contribute to the encoding process and therefore are of particular interest when considering learning strategies for kanji acquisition as we want to implement learning strategies that will assist in the encoding process of kanji.

One important aspect of the depth of processing theory is that 'meaningfulness' is said to be a significant contributor to deepening the level of processing. This has a direct impact on second language acquisition and kanji acquisition. According to Steinberg and Yamada (1978) meaningfulness is interpreted as being much more important in learning writing symbols than is perceptual complexity. Fukuzawa (1976, cited in Steinberg and Yamada 1978) found that meaning and not perceptual complexity mainly determined the acquisition rate of kanji for elementary and middle school children. In order to help learners gain a sense of control over a complex and enormous task, Findley and Cooper (1983, cited in Yamashita \& Maru, 2000, p. 160) conclude that the teacher must break the task into meaningful and tangible subsets. Applying this principle to teaching kanji translates into two strategies. One is that teachers must select characters that are meaningful and introduce them in an effective order, while providing students helpful information for learning each character (Hammerly, 1985). The other is to train students to acquire strategies for learning new kanji so they can be active and independent learners. Some of the strategies based on cognitive theory are chunking and elaboration/association.

\subsection{Chunking}

Chunking is grouping of information. It relates to kanji acquisition because kanji can be broken down into separate components. In doing so, seemingly very complex kanji can be more easily learned. For example, if we were to take the kanji “想” (sou), at first sight it may seem like a complex kanji to the beginner, however, if we break it down into its separate components - “木” (ki), “目” (me), and “心” (kokoro), it becomes much less daunting to the student of kanji. This is particularly so if the student is already familiar with the separate components. In the case of the kanji “想” the three separate components are in and of themselves independent kanji which are generally taught to beginner to lower intermediate students. In this way, by chunking kanji down into simpler less complex components, students improve their awareness of the structure of the kanji. This approach can be taken with many kanji and is the approach often adopted when implementing mnemonics as a learning strategy.

Psycholinguistic studies have demonstrated that learning unorganized random entities is difficult (Yamashita \& Maru, 2000). In the case of kanji, without any systematic order, they can appear to be a random array of lines and curves. The role of organization and its effect on memory is pertinent as we consider how different sequences of kanji effect kanji retention. It is also of importance to the paper that kanji order will indeed affect kanji retention and different sequences will produce greater success rates in retention. Chase and Simon (1973, cited in Yamashita \& Maru, 2000, p. 160), did a study on chess players and found that experienced chess players could not remember randomly placed chess pieces whereas they could remember pieces arranged in legal positions, suggesting that random information affects visual information processing and memory. Yamashita and Maru (2000) claim that learning hundreds of kanji by rote makes them seem like an endless stream of such entities, because without proper guidance the characters are nothing but complex, seemingly arbitrary combinations of bars and boxes, and their correspondences with meanings and readings are random.

Numerous manipulations have been shown to improve subjects' memory in recalling a long list of items. Many such devices involve organizing the material in such a way that subjects can systematically search their memories for the items (Anderson, 1985). If such is the case, organizing kanji in a systematic order should also produce greater rates of retention.

\subsection{Elaboration/Association}

Elaboration/Association is the process of relating new language information to concepts already in memory, 
Tackling the Kanji hurdle: Investigation of Kanji learning in Non-Kanji background learners or relating one piece of information to another, to create associations in memory (Oxford, 1990 p. 41 ). Elaboration is the process of adding more extensive information into the memory system. This serves to make existing information and incoming information more distinctive and unique. Yamashita and Maru (2000) found that results of a questionnaire-style experiment indicate that students find it easy to learn those kanji that they can relate to their previous knowledge and those that are particularly memorable. If we apply this concept of elaboration to English spelling, most would acknowledge that it would be better to first learn how to spell a simpler less complex word such as "cat" before one attempted to learn a more complex word such as "catastrophe." Regardless of the fact that there is no relation in meaning between these two words, learning the shorter less complex word first becomes a building block from which the student can go on to learn more complex words.

In kanji learning however, it is frequently the case that a more visually complex kanji is learned prior to a less visually complex character. For example, the kanji 店 (mise/shop) is in most cases learned before the kanji 占 (uranau/fortune-telling) despite the fact that the second kanji is both visually less complex and is a component of the first kanji. The basis for learning these particular kanji in this order is that the kanji for shop is a more frequently used kanji and is therefore more useful. However, if we consider elaboration as a useful technique for retaining information, it may be more systematic and efficient for JFL learners to learn the visually simpler kanji first regardless of the functional qualities of the kanji. This is especially so if at some stage the student will be required to learn the kanji for fortune-telling anyway.

Elaboration therefore is a pertinent concept to consider when deciding which order to introduce kanji to the JFL student. Of course, student objectives will also play a role in determining which approach is appropriate. An emphasis on more functional vocabulary may be a better approach for those JFL learners who only wish to acquire a conversational level of proficiency. Nevertheless, the concept of elaboration and its role in memory retention suggests that consideration for this concept will assist in retention and a kanji order that gives consideration to this concept may be more efficient then a random organization of kanji, regardless of the functional qualities of those kanji.

\subsection{Kanji Learning Strategies}

A language learning strategy is a conscious technique used by a learner to purposely assist the language learning process (Grainger, 2005). The Strategy Inventory for Language Learning (SILL) (Oxford, 1990) is a guide to different strategies for language learning; however, Grainger (2005) identifies a number of problems with applying the SILL to learners of Japanese due to special characteristics of the Japanese language and concludes that SILL is not in fact appropriate for use with orthographic languages like Japanese. A significant improvement was made on SILL for learners of kanji by Bourke (1997) with her establishment of the Strategy Inventory for Learning Kanji (SILK). SILK provides a list of 56 possible ways of processing kanji and managing kanji learning (Bourke \& Anderson, 2007).

Bourke (1996) found that the most successful students in kanji recall tasks were the ones who used the highest number and widest variety of strategies. It is beyond the scope of this paper to consider all 56 different strategies outlined in SILK; however, as noted by Shimizu and Green (2002), conventional strategies for learning kanji often include rote learning, contextual, and mnemonic. We will therefore look at each of these in turn.

\subsection{Rote Learning}

Gamage (2003) found that JFL learners from alphabetic backgrounds used repeated writing strategies to memorize kanji words more than learners from Chinese character backgrounds (See also Mori, 2003, p. 452). The main method encouraged for learning kanji for native Japanese in Japanese schools seems to be in the form of rote learning. Considering then that even after 12 years of studying kanji even Japanese native speakers have difficulty with the Jouyou Kanji, you would think it would be difficult to convince many foreign learners of 
Japanese to study kanji in the same way as Japanese native speakers do. Yet, rote learning seems to be the principle method used by foreign learners to remember the writing of the kanji. In a study done by Shimizu and Green (2002), Shimizu found that the rote learning strategy was the most commonly used by students of Japanese for kanji study. Shimizu points out that part of the reason for the popularity of rote learning as a learning strategy might be due to the fact that many native Japanese teachers draw on their own experiences when teaching kanji and most of them learned by using rote methods. Furthermore, rote learning is not an uncommon method used by native English speakers to remember the spelling of English words and this therefore may also be a factor in why so many students choose to use this learning strategy to remember kanji.

Rote learning, however, can be a useful method in helping to remember the kanji as it not only helps students to remember the kanji but can help students in developing their ability to write kanjis with the correct proportions. Nesbitt (2009) suggests that rote learning be used in the first year of kanji learning as a specific, structured learning-tool to develop strong neural pathways for automaticity. Clearly, rote learning will continue to have its place as a kanji learning strategy; however, studies seem to suggest that it is not particularly effective in improving retention.

\subsection{Mnemonics}

The use of mnemonics in kanji learning involves the use of keywords to represent individual components of a kanji. By combining these keywords into a sentence, students have a useful tool to help remember the kanji. James Heisig's book, "Remembering the Kanji" is probably the most well-known book on kanji to have taken the approach of using mnemonics to remember the kanji. The use of mnemonics as a kanji learning strategy seems to be gaining in popularity. Despite this, there seems to be little evidence to suggest that mnemonics aid in long-term memory retention. Wang and Thomas (1992) found that there was no greater advantage in memory recall with mnemonics over rote learning and in fact in their study, there was greater forgetting among the learners who used mnemonics. Wang does however recognize the advantages of mnemonics in learning and immediate recall but found no evidence to suggest that keyword mnemonics confer any long-term advantages.

Manalo, Mizutani, and Trafford (2004, cited in Mori \& Mori 2011, p. 450) found that mnemonic strategy introduction has a positive impact on learner perceptions, rather than on test performance as such. Although mnemonics may assist readers in remembering the structure of individual kanji, it cannot give the readers semantic and phonological information across kanji (Toyoda, 2011). This is one of the major criticisms of mnemonics as a learning strategy, although it may be useful in helping students remember the structure of the kanji, it does not aid students in remembering the reading of the kanji. Indeed, Heisig's book does not teach the readings of the kanji.

There still seems to be a lack of evidence to support the advantages of mnemonics as a learning strategy. Nevertheless, the growing popularity of this method should be sufficient evidence to suggest that for some people it is indeed an effective learning strategy. Shimizu and Green (2002) maintain that the important underlying concept of mnemonics as a learning strategy is the possibility of making the learning of new kanji more meaningful if they are presented within the context of a student's previous knowledge. This is consistent with the theory of elaboration and suggests further evidence to support the effectiveness of mnemonics as a learning strategy.

\subsection{Contextual}

Studying kanji in context is a popular learning strategy for kanji study and evidence of this can be seen in the number popular kanji textbooks on the market that adopt this approach; notably, Chieko Kano's books "Basic Kanji Book," "Intermediate Kanji Book," and "Kanji in Context” published by Japan Times.

The basis for this approach is that kanji should be treated as "vocabulary" rather than an "alphabet". This is frequently the approach taken for kanji education at intermediate levels. Kano (1995) asserts that the goal of 
Tackling the Kanji hurdle: Investigation of Kanji learning in Non-Kanji background learners

kanji education at the intermediate level should be efficient vocabulary building with kanji use words rather than the teaching of kanji as characters. According to Shimizu and Green (2002), contextual strategies have been emphasized because the reading and meaning of kanji compounds are often highly context dependent. With the large number of homonyms in the Japanese language, studying kanji in context as opposed to just studying individual kanji isolated from any context whatsoever is a useful strategy for the student of kanji.

\section{Kanji Ordering Strategies}

There are several criteria which can be considered when selecting kanji to be introduced to beginning students of Japanese. However, the order is rarely given any consideration at all and kanji are most often introduced in the order they appear in the textbook or the order as prescribed by the Japanese Ministry of Education. Visual, phonological, contextual, stroke number and frequency are all criteria from which kanji can be ordered. In cases where a particular learning strategy is in use, the learning strategy will lend itself better to a particular order. In this section, we will consider possible ways that kanji can be ordered systematically and their potential to be implemented as an efficient learning strategy for JFL learners from non-kanji backgrounds. For the purpose of this paper, a kanji ordering strategy will be any order of kanji that is introduced as a learning strategy in and of itself and or in conjunction with other learning strategies. Ordering strategies for kanji provide a means by which kanji can be given more meaning and therefore serve as a useful kanji learning strategy. This section will examine the following areas: pictographs/etymological based criteria, component based criteria, frequency based criteria, form based criteria, and other kanji orders.

\subsection{Pictographs/Etymological Based Instruction}

In many Japanese courses the most common approach for teaching kanji is to begin by teaching the etymology of the kanji. The etymology of the kanji is however only practical for kanji which come under the category of pictographs (象形文字 shoukeimoji). For some kanji, it is very easy to see the visual formation of the kanji from its intended form and this is both interesting for students and a useful memory aid. Hatasa (1989) found that the meanings of pictographs were easier to remember than non-pictographic characters. In ease-of-learning ratings from, a questionnaire conducted by Yamashita and Maru (2000), pictographs were rated higher than all other types. The findings of Yamashita and Maru support previous proposals that pictographs should be taught at the earlier stages of kanji learning (Takebe, 1989; Hatasa, 1989).

Despite being useful in the early stages of learning, there are difficulties associated with etymology based instruction which make etymology, as a criterion for ordering kanji and as a teaching methodology, very limited. Firstly, pictographs only make up a small percentage of kanji and therefore its application is limited to a small percentage of characters. Secondly, many kanji have undergone changes over time and frequently, therefore, bear little resemblance to their original form and intended meaning. For example, the kanji “業” (gyou, waza/profession, deed) was originally written to depict a base and notched board of a musical instrument (Henshall, 1998, p. 75). Thus, the original meanings of this kanji and its form have both changed over time making its etymology of little use in the task of memorizing kanji for the JFL student. Etymology is of course a useful teaching tool for those kanji which still closely resemble their original form, such as the kanji “日” (hi/day) and “目” (meleye).

The kanji below provide an example of kanji grouped based on etymology. As explained above, the number of pictographs is limited and therefore etymology based instruction would only be applicable for those such kanji. Etymology therefore does not offer a method for ordering all of the jouyou kanji. Nevertheless, learning the pictographs first and together before any other kanji may be a useful approach.

Etymology Based Order(All Pictographs taken from grade 5 syllabus)

益、久、再、支、示、者、率 
All the above kanji share the characteristic of being pictographs. Pictographs are generally thought to be the best characters to introduce students to first. Nevertheless, from the random group chosen above, many of the kanji do not resemble their original form and therefore may not necessarily offer and advantages to the JFL student. The average stroke number for each character in this group is six strokes.

\subsection{Component based criteria}

Many of the pictographs and visually less complex kanji are made up of one component; however, kanji are often comprised of two or more separate components. Components are frequently radicals or independent standalone kanji. For example, the kanji “続” (tsuzuku,zoku/continue) is a kanji that could be said to be comprised of two components: (1) “系” the radical 糸偏 (itohen) also a standalone kanji “糸” (ito/string) (2) “売” the independent kanji for 売る (uru, bai/sell).

Many approaches have been taken to learn kanji by analyzing the components of kanji as opposed to trying to learn the whole kanji as a single entity. Most notably, Kaiho (1990), Takebe (1991), De Roo (1986), Heisig (1986) and Takagi (1993) have all challenged traditional approaches to kanji learning for learners from non-kanji backgrounds and have encouraged component based approaches (Noguchi, 1995). As the more complex kanji are made up of less complex forms, introducing kanji that can build upon each other creates a system in which there is a logical progression for the learner as opposed to the frequency-based order which may seem somewhat random.

Evidence demonstrates that learners retain new kanji characters better using componential analysis (Kubota \& Toyoda, cited in Toyoda, 2011). The order in which kanji are introduced to second language learners is, as discussed earlier, most often based on either their frequency of use or the order which they appear in the course rather than on any structural features of the characters (Taft \& Chung, 1999). Inevitably, some simple characters which act as radicals for more complex characters are introduced first, but as we saw with the case of the character “占”, that is not always the case. Taft and Chung (1999) citing evidence that radicals do play a significant role in recognition of Chinese characters by adult native readers note that, if expert Chinese readers make use of radical structure when reading, it seems sensible to suggest that learning would be facilitated if this structure were explicitly highlighted when teaching characters to novices.

In an experiment by Taft and Chung (1999), they found that awareness of radicals facilitates the learning of Chinese characters even after only a brief exposure to radical structure. Taft and Chung (1999) further conclude that getting students to learn complex characters as whole entities, without a systematic emphasis on their radical structure, is not the most effective method of teaching characters.

One advantage of knowing the kanji components is that more complex kanji can be broken down into more easily remembered components. Traditionally, kanji for Japanese kanji dictionaries are located by the 214 部首 (bushu) or "radicals." This method of locating kanji, although practical for native Japanese speakers or foreign students with a high degree of familiarity with kanji, is of little use to beginner Japanese students as it requires the student to be able to correctly determine the radical of a kanji. One possible approach is for students of Japanese to learn the radicals prior to learning any other kanji. In addition to serving as kanji components, some radicals (approximately 98 of the 214), are also independent general-use jouyou kanji. This would mean that by learning the radicals first, students would have mastered a number of independent kanji and radicals that are components of more complex kanji.

Yamashita and Maru (2000) postulate that incorporating compositional features in the Japanese language curriculum may be part of an effective approach to kanji instruction. By teaching kanji by giving attention to appropriate compositional features of kanji, each character becomes a meaningful unit opposed to an arbitrary combination of lines (Yamashita \& Maru, 2000). Yamashita and Maru (2000) conducted a survey to determine whether beginning JFL students regarded certain groups of kanji with compositional features as easy to learn or not. The groups of kanji tested were grouped according to four compositional features: 
Tackling the Kanji hurdle: Investigation of Kanji learning in Non-Kanji background learners

1. Pictograph

2. Katakana composites (kanji comprised of two katakana characters, eg. “加”)

3. Semantic-phonetics (kanji in which one part indicates meaning and the other part represents the reading)

4. Semantic composites (kanji that represent the integrated meaning of its components, eg. “好”).

Yamashita and Maru's test found that students regarded pictographs as the easiest to learn followed by katakana and semantic composites. Semantic-phonetics were rated the lowest. Yamashita and Maru also found that there was a correlation between the number of strokes and the rating with those kanji with more strokes as rated more difficult.

The significance of Yamashita and Maru's study is that it provides evidence that compositional features of kanji affect students' perceptions of characters . Furthermore, Yamashita and Maru (2000) identify two pertinent points from their study. Firstly, beginning students perceive as easy to learn those compositional features that they can identify with already existing concepts, and, secondly, information that makes learning meaningful appeals to learners.

\section{Element/Component Based order (mutual components)}

$$
\text { 王、玉、宝、珠、現、狂、皇 }
$$

The above kanji were taken from Heisig (2001, pp.107-110). The kanji above all share the common character “王” and therefore after learning the first character it would seem likely that the other kanji are easier to remember. The average stroke number for each kanji in this group is eight strokes.

\section{Radical Based Order (mutual radical)}

$$
\text { 針、釣、鈍、鉛、鉱、鉄、錰 }
$$

This group is similar to the above group in that each character shares a common component, in this case, “金” . In this group however the common character is the radical and is in the same position for each character unlike the component based order in which the component changes position. The average stroke number for characters in this group is twelve. Bear in mind that, in this group, the radical consists of eight strokes in and of itself.

\subsection{Frequency Based}

The order of the everyday kanji as set out by the Japanese Ministry of Education is one based on frequency of usage and consequently may aid students in reading comprehension by familiarizing them with the most frequently used kanji first. Pye (1971) regarded this approach as a much more sensible criterion on which to base one's study. It, however, has little application to the writing process of kanji, and, is of little use to the foreign learner whose exposure to Japanese written script is mostly restricted to their textbook. Indeed, it is the foreign learners' lack of exposure to kanji in everyday life away from the Japanese class that is partly responsible for impeding faster progress in kanji acquisition.

Teaching kanji in an order based on their frequency of use means that at some stages students will learn more visually complex kanji before visually less complex kanji. This is despite the fact that less complex kanji will often be a component of the more complex yet albeit more frequently used kanji. For example, in the order outlined by the Japanese Ministry of Education, the kanji 店 and 点 are taught before 占(Noguchi, 1995). Clearly, 占 is the least visually complex kanji of the three and a component of the other two. If we learn by comparing new knowledge to the knowledge we already have, then, teaching the less complex kanji first would be the better option. Yet, teaching kanji on the frequency-based order remains the most common method in kanji textbooks. 
The assumption that the frequency-based order of teaching kanji is the best for foreign learners of Japanese because it is the one used by native Japanese is flawed because as Hatasa (1989) notes, in the case of non-native learners of Japanese, the study of both verbal language and written language takes place almost simultaneously. Frequency of kanji has limited applicability as well because, unlike Japanese children, non-native learners of Japanese only see kanji in their Japanese textbooks, not in textbooks for other subject matters or generally in their everyday environment.

As Unger, (2006) notes, the principal difficulty of the Japanese writing system lies in the fact that typical kanji can have multiple readings. Unger (2006) also notes that the higher its frequency of occurrence, the more readings a kanji is likely to take. He gives the kanji, 日, as an example of a kanji frequently used that has multiple readings.

Perhaps an even better example is the kanji “生” (sei/live) and the kanji “下” (shita/under) which both have over ten different readings per kanji. If Unger is correct in his assessment, then, teaching the more frequently used kanji which have multiple readings may be another reason why teaching kanji in a frequency based order is troublesome and perhaps not the best criteria for ordering kanji for JFL students. In saying this, it is not necessary for beginning students to learn all of the readings for the one kanji when initially learning it as some of the readings are not commonly used and it is therefore feasible to return to that kanji at a later date to learn the less commonly used readings. This is often the case in the Japanese education system in which students learn the readings for a kanji in junior high school and learn more complex usage and readings of the same kanji at high school. For example, students learn the kanji “鑑” as "kan" in junior high school and learn the more advanced reading for the same kanji - 鑑みる (kangamiru) in high school.

Scott Alprin in "Teaching Kanji Components: Using An Element-Based Approach in Class," has the following to say in regards to the "frequency based approach":

"It is my opinion that textbooks generally follow the Monbusho example, and do not usually dare to teach a kanji that is not considered "important" in beginning levels. It is my contention that this makes sense for Japanese children, but not necessarily for Western teenage and college students. It seems unfortunate to me that the "frequency-based approach" is so mainstream that very simple kanji that could act as building blocks for "important" kanji are virtually ignored under the "frequency-based approach."(Alprin, 2002 )

Although not without merit, there seems to be sufficient support to suggest that a frequency based order for teaching kanji is perhaps not always the most appropriate criterion for ordering kanji for students from non-kanji backgrounds.

\section{Ministry of Education Prescribed Order (Frequency Based)}

$$
\text { 圧、移、因、永、棠、衛、易、益、液、演（Grade } 5 \text { primary school kanji） }
$$

The kanji in the list above are taken from the kanji for grade five elementary school children. There appears to be little in common amongst these kanji except for the radical in the last two kanji being the same (さんずい /sanzui/water radical). It is hard to see how studying kanji in this order offers any advantages to students by making them easy to remember. Nevertheless, this is the order used by native Japanese speakers.

\subsection{Form Based}

The visual aspects of kanji are often overlooked as criteria for the order in which kanji are introduced. More often than not, the visual element of kanji is considered to be one that assumes a kanji with fewer strokes is easier to remember than one with many.

Obviously, the number of strokes in a kanji can play a part in determining its level of difficulty. Such is the

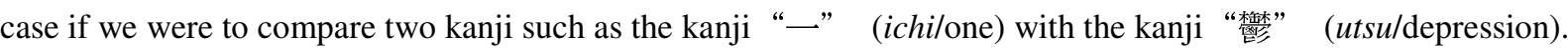


Clearly, the first kanji is much easier than the second. Yamashita and Maru (2000) also found as a result of their own study that strokes with more strokes were regarded as harder to learn in their study. However, it is not always the case that kanji with more strokes are harder to remember. Tollini (1994) cites the following kanji as an example:

1. 扼、処、矛、炒

2. 高、員、益、容

The kanji in the second list have a greater number of strokes but are more easily recognizable than the kanji in the first list. According to Tollini (1994), the form (字形) of a kanji is an important element that requires consideration when selecting kanji to be introduced. Tollini (1994, p. 107) asserts that, "Western students who have no familiarity with kanji can recognize and memorize better those kanji whose form is easily distinguishable and is in accordance with the visual recognition laws of western people." According to Tollini (1994), one of the problems for students of Japanese from alphabet-based languages is they try to approach kanji according to the decoding rules for the alphabet and can therefore not treat kanji adequately. Tollini (1994, p. 108) notes that western students can better recognize certain forms due to their "visual habits." Tollini (1994) goes on to say that if we can better understand how westerners see kanji then we can identify kanji which are more easily recognizable to westerners and introduce those kanji in the initial stages.

What forms then exactly are important considerations? According to the results of an experiment by Tollini, Westerners employ relatively simple visual criteria -Horizontal, vertical, and homogeneous forms (Tollini, 1994). One might think that Tollini's emphasis on the form of kanji suggests that he is advocating the components/element based approach to studying kanji. However, on the contrary, Tollini asserts that the division of kanji according to component parts is irrelevant, because it does not fit into the universal laws of recognition" (Tollini, 1994, p. 112) Nevertheless, Tollini does advocate teaching component parts as they enhance the learning process (1994).

\subsection{Form Based Order}

$$
\text { 果、界、花、辛、赤、当、異 }
$$

The kanji in this group were taken from an experiment by Tollini (1994, p. 112) in which participants who were completely unfamiliar with kanji were asked to draw a single pencil line through each kanji to divide it in a place they felt appropriate. The kanji above received a high score for both horizontal and vertical division. Furthermore, as Tollini notes, all of these kanji have a high degree of vertical symmetry but also have a clear horizontal divisibility (1994). The typology of kanji is something that is often neglected when considering which kanji to introduce to students, however, consideration to symmetry and the form of the kanji may present some advantages to students. No studies to this author's knowledge have however be conducted to confirm this. The average stroke number for characters in this group is eight.

\subsection{Other Kanji Orders}

In this section we will briefly consider some other specific examples of possible kanji orders, looking at groups of kanji based on different criteria. It is at the core of this thesis to examine whether presenting kanji in a particular order offers any advantages for memorization. There will be a certain degree of overlap between the orders, that is, one particular order may potentially fulfill two different criteria.

Context Based Order (All kanji represent parts of the body)

$$
\text { 手、足、首、䫓、耳、鼻、 } \square
$$

In this group, all kanji represent parts of the body, hand, leg, head, face, etc. This may offer students the 
advantage of being able to store information in an organized fashion. Beyond this, it doesn't seem to offer and obvious advantages. The average stroke number for characters in this group is eight strokes.

\section{Concluding remarks}

Foreign learners of kanji are at a vast disadvantage in the kanji learning process as their exposure to kanji is very limited to their Japanese textbook and classroom and whatever time they can find for individual study. It is therefore important that we seek out more efficient methods of kanji instruction and helpful learning strategies. Yamashita and Maru (2000) note that what is necessary is careful, systematic investigation of correlations between the manners in which kanji are introduced and how well they are acquired. Yamashita and Maru (2000) in discussing the implications of their own study suggest that one possible way to apply the findings to teaching would be to use them in selecting characters and deciding the order in which to teach them. This indeed is the motivation for this research and it is hoped that this research will improve our understanding of how to best select and order kanji for JFL students.

The significance of this research is that it highlights several factors that influence learning and retention of kanji and provides a criterion for introducing kanji in different orders. The results of this study have some implications for JFL course designer, teachers as well as learners. The implication for course designers and teachers is that they can experiment with introducing kanji in different orders based on these criterions and adopt a more systemised order for introducing kanji that maximises students' ability to learn and retain kanji. The obvious implications for JFL students from non-kanji backgrounds is a more systemised approach to learning kanji which incorporates a more logical order and therefore making the task of learning kanji both more manageable and less daunting.

\subsection{Future Research}

The authors of this paper is in agreement with Tollini (1994, p.115) when he notes that, in the future, more research, both theoretical and practical, should be carried out in order to understand how kanji can be better learned by western students. As it seems that Japanese language teachers frequently introduce kanji in the order they appear in textbooks, an analysis of popular kanji textbooks would be beneficial in understanding the current approaches and their relative merits.

\section{References}

Alprin, S. (2002). Teaching kanji components: Using an element-based approach in class. http://www.sabotenweb.com/bookmarks/about/scott.html

Anderson, J. R. (1985). Cognitive psychology and its implications. New York: Freeman and Company. Baddeley, A. D. (1999). Essentials of human memory. East Sussex: Psychology Press.

Bourke, B. (1996). Maximising efficiency in the kanji learning task. Unpublished doctoral dissertation, The University of Queensland

Craik, F. I. M., \& Lockhart, R. S. (1972). Levels of processing: A framework for memory research. Journal of Verbal Learning and Verbal Behavior, 11(6), 671-684. http://dx.doi.org/10.1016/S0022-5371(72)80001-X

Douglas, M. O. (1992). Development of orthography-related reading and writing strategies by learners of Japanese as a foreign language. PhD Dissertation, University of Southern California.

Gamage, G. H. (2003). Issues in strategy classifications in language learning: A framework for kanji learning strategy research. ASAA E-Journal of Asian Linguistics \&Language Teaching 5, 1-15.

Gamage, G. H (2003). Perceptions of kanji learning strategies: Do they differ among Chinese character and alphabetic background learners?. Australian Review of Applied Linguistics, 26 (2), 17-30.

Grainger, P. (2005). Second language learning strategies and Japanese: Does orthography make a difference? System 33, 327-339. http://dx.doi.org/10.1016/j.system.2005.01.003 
Tackling the Kanji hurdle: Investigation of Kanji learning in Non-Kanji background learners

Hammerly, H. (1985). An integrated theory of language teaching and its practical consequences. Blaine, WA:

Second Language Publications.

Hatasa, K. (1989). A study of learning and teaching of kanji for non-native learners of Japanese. Unpublished Doctoral Thesis, University of Illinois at Urbana-Champaign.

Heisig, J. W. (2001). Remembering the kanji, Tokyo: Japan Publications Trading Co. Ltd.

Henshall, K. G. (1988). A guide to remembering Japanese characters. Rutland, Vt.: C.E. Tuttle.

Iwashita, N. (2009). Effects of learner background on the development of writing skills in Japanese as a second language. Australian Review of Applied Linguistics, 32(1), 03.01-03.20. http://dx.doi.org/10.2104/aral0903

Survey Report on Japanese-Language Education Abroad. (2009). Present condition of overseas Japanese-language education, Japan Foundation

Kano, C. (1995). Development of intermediate kanji textbooks [Chuukyuu Kanji kyouzai no Kaihatsu], Koide Kinen Nihongo Kyouiku Kenkyuu Kai No. 03, 65-72.

Kano, C. (2003) Basic kanji book. Tokyo: Bonjinsha

Kano, C. (2003). Intermediate kanji book. Tokyo:_Bojinsha.

Ke, C. (1998). Effects of language background on the learning of Chinese characters among foreign language students. Foreign Language Annals, 31(1), 91-102. http://dx.doi.org/10.1111/j.1944-9720.1998.tb01335.x

Kess, J. F. (1999). The Japanese mental lexicon: Psycholinguistic studies of kana and kanji processing. Amsterdam: John Benjamins.

Kindaichi, H. (1978). The Japanese language. Tokyo: Tuttle.

Klatzky, R. L. (1980). Human memory: Structures and processes. New York: W.H. Freeman and Company.

Maftoon, A. \& Shakori., N. (2013). Relationship between learners' beliefs system and the choice of language learning strategies: A critical study. The International Journal of Research Studies in Language Learning, 2(2), 39-48.

Miller, R. A. (1971). Japanese and the other Altaic languages. xviii, Chicago and London: University of Chicago Press

Mori, Y. (2003). The roles of context and word morphology in learning new kanji words. The Modern Language Journal, 87(iii), 404-420. http://dx.doi.org/10.1111/1540-4781.00198

Mori, Y., \& Mori, J. (2011). "Review of recent research (2000-2010) on learning and instruction with specific reference to L2 Japanese." Language Teaching, 44(04), 447-484. http://dx.doi.org/10.1017/S0261444811000292

Nesbitt, D. (2009). Achieving unconscious recall of kanji: Can rote learning help? New Zealand Studies in Applied Linguistics, 15(2), 61-73.

Noguchi, M. S. (1995). Component analysis of kanji for learners from non-kanji using countries. The Language Teacher, 19(10),

Oxford, R. L. (1990). Language learning strategies: What every teacher should know. New York: Newbury House.

Pye, M. (1971). The study of kanji. Tokyo: The Hokuseido Press.

Rajaee, N. M. \& Abbaspour, E. \& Zare, J. (2013). A critical review of recent trends in second language syllabus design and curriculum development. The International Journal of Research Studies in Language Learning, 2(2), 63-82.

Shimizu, H., \& Green, K. E. (2002). Japanese language educators' strategies for and attitudes toward teaching kanji. The Modern Language Journal, 86(2), 227-241. http://dx.doi.org/10.1111/1540-4781.00146

Steinberg, D. D., \&.Yamada, J. (1978-1979). Are whole word kanji easier to learn than syllable kana? Reading Research Quarterly, 14(1), 88-99. http://dx.doi.org/10.2307/747295

Taft, M., \& Chung, K. (1999). Using radicals in teaching Chinese characters to second language learners. Psychologia, 42, 243-251.

Takagi, H. (1995). Study of kanji pattern recognition and kanji acquisition among non-kanji area students. 
Japanese Language Education Around the Globe 5, 125-138.

Takebe, Y. (1989). A method for teaching kanji [Kanji no oshiekata]. Tokyo: ALC Press Incorporated.

Tollini, A. (1994). The importance of form in the teaching of kanji. Sekai no nihongo kyouiku 4, 107-116.

Toyoda, E., \& McNamara, T. (2011). Character recognition among English-speaking L2 readers of Japanese. International Journal of Applied Linguistics 21(3), 383-406. http://dx.doi.org/10.1111/j.1473-4192.2011.00285.x

Unger, J. M. (2006). Japan: Writing system. Encyclopedia of Language \&amp; Linguistics (2nd ed.). B. Editor-in-Chief: Keith. Oxford, Elsevier: 95-102.

Usuki, M. (2000). Promoting learner autonomy: Learning from the Japanese language learners' perspectives. Research Report, Hokuriku University, Japan.

Wang, A. Y., \& Thomas, M. H. (1992). The effect of imagery-based mnemonics on the long-term retention of Chinese characters. Language Learning, 42(3), 359-376. http://dx.doi.org/10.1111/j.1467-1770.1992.tb01340.x

Yamashita, H., \& Maru, Y. (2000). Compositional features of kanji for effective instruction. The Journal of the Association of Teachers of Japanese, 34(2), 159-178. http://dx.doi.org/10.2307/489552 